\title{
SCIDOC
}

International Journal of Dentistry and Oral Science (IJDOS)

ISSN: 2377-8075

\section{Effects of Fluoridated Tooth Paste on Medically Erosive Enamel in Banded Primary Teeth during Maxillary Arch Expansion in Cleft Palate Patients: An In Vitro Study}

Research Article

Aisha Akram Qasim¹, Baraa W Alani², Sarmad S. Salih Al Qassar ${ }^{3}$

${ }^{1}$ Assistant Professor, Department of Pedo Ortho Prevention, College of Dentistry, University of Mosul, Mosul, Iraq.

${ }^{2}$ Assistant lecture, Department of Pedo Ortho Prevention, College of Dentistry, University of Mosul, Mosul, Iraq.

${ }^{3}$ Lecture, Department of Pedo Ortho Prevention, College of Dentistry, University of Mosul, Mosul, Iraq.

\section{Abstract}

\begin{abstract}
Introduction: This study searched to validate the gravimetric method on the evaluation of enamel erosion of different pediatric liquid medicaments on deciduous molars encircled by orthodontic bands, and the effects of fluoridated toothpaste on this eroded enamel.

Method: A suitable orthodontic band was used to band each of 110 non-carious exfoliated deciduous molars, and stored in artificial saliva. These teeth were divided into: fluoridated and non-fluoridated groups (50 teeth each), and ten teeth were used asnegative controls. The enamel surface of the fluoridated group was swabbed with fluoridated toothpaste for five minutes twice daily. Each group was sub divided into five clusters, of tenteeth each according to the type of medication used which included paracetamol, Adol, amoxicillin, Medazole and ViTon, according to a specific immersion cycle. The erosion induced in the enamel for all teeth was evaluated by gravimetric analysis for different intervals.

Results: The results showed that the weight loss increased with increasing exposure to liquid medication for all groups, but this increase was smaller in the fluoridated group. The highest mean weight loss after 28 hours was in ViTon, and the lowest was in Medazole[0.145 (0.005); 0.08 (0.008)] respectively.

Conclusion: Gravimetric method is a valid method for detection of the eroded enamel induced by liquid medications on banded deciduous molars, and fluoridated toothpaste significantly reduced such erosion potential.
\end{abstract}

Keywords: Gravimetric Analysis; Orthodontic Band; Deciduous Teeth; Erosion; Liquid Medications.

\section{Introduction}

Children born with a cleft palate have transverse maxillary constrictions problems [1]. Furthermore, about $8 \%$ of newborn normal children around the globe also present from this transverse maxillary narrowing [2], that is expressed by dental glossary as uni- or bi- lateral posterior cross bite. A palatal expander (PE) could be the only appropriate method to treat these transverse deficiencies [3]. Some clinicians suggest that PE use is mandatory in cleft palate children and the early correction of the transverse posterior cross bite is essential in young children [4]. This is specifically in order to relocate the follicles of the permanent teeth to a more satisfactory position, and to increase the potential for re-establishment of normal occlusal relations in the molars $[4,5]$.

The anchorage onto the deciduous molars seems to be the appro- priate option for early treatment. This could be due to the delay eruption of the upper first permanent molar. The deciduous second molars and the deciduous canines replacing the permanent teeth for the PE support [5]. However, the effectiveness of this modifications on the PE has been reported by some authors [6-8]. The replacing of first permanent molars has some negative side effects during orthodontic treatment [6]. So, early management using a Haas expander anchored by the deciduous molars and canines could be acceptable for transverse cross bite resolution as well as for upper anterior teeth crowding enhancement, as it has a simple design and treatment administration [6,9]. Banding of the deciduous molars in space maintainer is also important as a prophylaxis for further orthodontic problems.

Enamel erosion has beendocumented as a problem affecting all age groups $[10,11]$. Particularly, enamel wearing that is produced

*Corresponding Author:

Dr. Sarmad S. Salih Al Qassar,

Lecture, Department of Pedo Ortho Prevention, College of Dentistry, University of Mosul, Mosul, Iraq.

Tel: 009647701712447

E-mail: sarmadsobhi@yahoo.com/sarmadsobhi@uomosul.edu.iq

Received: December 01, 2020

Accepted: December 30, 2020

Published: January 12, 2021

Citation: Aisha Akram Qasim, Baraa W Alani, Sarmad S. Salih Al Qassar. Effects of Fluoridated Tooth Paste on Medically Erosive Enamel in Banded Primary Teeth during Maxillary Arch Expansion in Cleft Palate Patients: An In Vitro Study. Int J Dentistry Oral Sci. 2021;8(1):1350-1355. doi: http://dx.doi.org/10.19070/2377-8075-21000267

Copyright: Sarmad S. Salih Al Qassar ${ }^{\circ}$ 2021. This is an open-access article distributed under the terms of the Creative Commons Attribution License, which permits unrestricted use, distribution and reproduction in any medium, provided the original author and source are credited. 
by diet as well as long term administration of low $\mathrm{pH}$ oral medication at early stage of life [12-14]. However, the active components of such oral medicaments are essential for enhancement and/or upkeep of health, at the same time, some of inactive ingredients have dangerous effects, like teeth erosion and caries [15]. Scan electron microscope and surface hardness were the only main methods used to evaluate the erosion on the tooth surface.

Since the erosive potential of sugared and acidic oral syrupsthat are recommended for daily application to children, especially for those wearing Hass expander or with space maintainer, the presence of the molar bands could increase the interjection possibility of retaining the medicine substrate over the deciduous molar for longer time than in normal situations. As a result, the incidence of dental erosion could be higher and the possibility of deciduous molars loss will be increased. Finally, the transverse maxillary and space lossproblems would be highly complicated.

\section{Aims}

The aims of this ex-vivo study were to assess the validity of gravimetric methodfor the evaluation of the potential hard tissue erosion of different pediatric liquid medicaments induced on the deciduous molars encircled by orthodontic bands. The effects of fluoridated toothpaste on this erosive enamel, was also investigated. Correspondingly, this study determined the $\mathrm{pH}$ of various liquid medicaments that are recommended for daily use by pediatric physicians.

\section{Materials and Method}

The protocol of this study was approved by Research Ethics Committee of the Collage of Dentistry/University of Mosul; approval no. 4S/1548 in 15/08/2018.

In this research, five different kinds of oral syrups that are recommended for daily use by pediatric physicians were used. These syrups included two analgesics (Paracetamol (PA) and Adol (AD)); one antibiotic (Amoxicillin (AM)); one antifungal (Medazole (ME)) and one iron supplement (ViTon (VI)). Table 1 shows the composition and the $\mathrm{pH}$ of these syrups. The $\mathrm{pH}$ values of these selected medicines at room temperature were measured using a pH meter (Digital pH \Ion - meter, Philips, Japan).

\section{Samples collections}

A total of 110 exfoliated non-carious deciduous molars were collected from the pediatric departments of the dental center at the Collage of Dentistry/University of Mosul. All the teeth were hand scaled and cleaned and well examined by a dentist for structural distortion that could hinder the outcome. Each tooth was banded with a suitable orthodontic band size (Dentaurum, Ispringen, Germany). Then, these bands were cemented by Fleck's selfcure Snow White zinc phosphate cement (Keystone Industries, Singen, Germany) and all the cement accessories were removed before teeth were stored in artificial saliva at $37^{\circ} \mathrm{C}$ for subsequent processing.

\section{Samples grouping}

The 110 final included teeth were divided into two experimental groups: fluoridated (FG) and non-fluoridated groups (NG) (50 teeth for each). While, remaining ten teeth were used as a negative control group. In the NG group, no material was added to the teeth surfaces. Whereas, in FG, the enamel surface of each tooth was swabbed with a thin layer of fluoridated tooth paste (Maclean training tooth paste, Glaxo Smith Kline, Brentford, U.K.) using a fine brush for 5 minutes. This procedure was performedtwice daily to simulate normal oral hygiene instructions, and then reimmersed in artificial saliva. Each experimental group was sub divided into five clusters of ten teeth each,According to the five types of medication used. Then, each of these clusters were exposed to the tested medications according to a specific immersion cycle (see below). Between each immersion cycle the teeth were re-stored in artificial saliva at $37^{\circ} \mathrm{C}$ for $24 \mathrm{~h}$ in separated incubators. The artificial saliva was prepared according to'Taqa et al [16] and its components are listed in Table 2.

\section{Immersion cycles}

The protocol of samples immersion was derived from previously published method subscribed by Kulkarni et al. [17] in which the occlusal surface of samples were adapted to simulate the daily consumptions, using special clamp to insure the inferior surface of the crown not soaked in the medication. Each tooth wasdipped for one minute in bottles containing $5 \mathrm{~mL}$ of the each syrup under investigation. This procedures were repeated three times per day with six hoursinterim between the immersion series. Then, the teeth were rinsed with deionized water and were well dried for erosive evaluation (see below). After each immersion cycle, the teeth were maintained in tenmilliliter of previously prepared saliva at $37^{\circ} \mathrm{C}$ until subsequent immersion phase. The syrups were renewed before each immersion series [17].

\section{Teetherosive evaluation}

The erosion of the deciduous teeth was evaluated using an updated method designated by Von Fraunhofer \& Rogers [18]. This method depends on the assessment of the weight loss of the tooth after exposure to the erosive factor. So, all teeth were well dried using blotting paper at room temperature for one hour and were then weighted using a calibrated accuracy balance (Sartorius BP61S, Göttingen, Germany), the metering precision was 0.1 $\mathrm{mg}$. The above procedures were repeated after 7, 14, 21, and 28 days intermissions, after the constant and regular repetition of the daily immersion series. The negative control group (tenteeth) were stored in the artificial saliva throughout the all experiment period (28 days), with regulardaily refreshment of artificial saliva for all clusters, as shown in figure 1 .

\section{Composition of toothpaste}

The toothpaste used in this study was composed by: Sodium mono-fluoro-phosphate (500 ppm fluoride), Sorbitol, Aqua, Hydrated silica, Glycerin, sorbitol, Titanium Dioxide, Sodium Lauryl Sulfate, Xanthan Gum, Di Soduium Phosphate, Aroma, Sodium Saccharin, Garrageenan, CaliciumGlycerophosphate, Limonine Cl77492, Ci77491. (Maclean training tooth paste, Glaxgo Smith Kline, Brentford, U.K.)

\section{Statistical evaluations}

The outcome data were typed into Excel sheet. The statistical ex- 
ploration was done using the statistical package for the Social Sciences software (version 19). The descriptive analysis was used to find the means and stranded deviation of weight loss for all the teeth and at different intervals. One ways ANOVA also was used to find the significant differences between the tested groups. P value was adjusted to be $<0.001$.

\section{Results}

The physiochemical properties and the $\mathrm{pH}$ of each pediatric medicinal syrups are presented in (Table 1). All the studied syrups were acidic on opening, although the $\mathrm{pH}$ of $\mathrm{ME}$ was higher than the $\mathrm{pH}$ of the remaining syrups (6.19). The $\mathrm{pH}$ of VI was lower than the $\mathrm{pH}$ of the remaining syrups (4.94).

Among all liquid medication, the mean of weight loss after 28 hours was the maximum in VI [0.145 SD (0.005)] while it was the least in ME [0.080 SD (0.008)]. On the other hand, NG had a higher teeth weight loss than FG under the same type of liquid medication used (Table 3).

Figure 2 shows that there was a considerableextent of weight loss of tooth in each medication, especially after 28 days. The graph also shows that the mean of total teeth weight loss was in the VI, when compared it with negative control group, the tooth weight loss was higher in VI after 7, 14, 21 and 28 days. However, other medication also, showed higher means for the total tooth weight loss, if wecompared it with negative control group. The result also showed that the weight loss increase with increasing the frequency of exposure to liquid medication for all groups.

\section{Discussion}

In this ex vivo study, the amount of erosion induced in the deciduous teeth was expressed as a weight loss. This gravimetric analysis method has been reported in the literatures and accepted internationally, as it is simple,feasible, and meaningful [19-21].

Recently, teeth erosion has been significantlydocumented as amainbasis of tooth structure loss in children and adolescents [22]. Especially, for banded deciduous molars used in expansions of the constricted maxilla or for space maintainer purposes. As the bands as well as all the components of the expander are consider a rough irregular surfaces that could retain the medications and food remnants and increase the time of exposures of these erosive materials on the teeth enamel. However, in this study we try to simulate the oral environments by banding the teeth with orthodontic bands before exposure to medicine.

The current research indicates that the investigated syrups could possibly erode the primary tooth enamel after the previously prescribed immersion phases, which could be dueto the mineral loss

Table 1. The Composition and the Mean $\mathrm{pH}$ of medication used in this study.

\begin{tabular}{|c|c|c|}
\hline The Medication & Composition & $\mathrm{pH}$ \\
\hline Paracetamol (PA) & Paracetamol $120 \mathrm{mg} / 5 \mathrm{Ml}$ & 5.11 \\
\hline Adol (AD) & $\begin{array}{c}\text { Paracetamol } 100 \mathrm{mg} / 1 \mathrm{ml} \\
\text { Excipients: } \\
\text { Propylene glycol, sorbitol, glycerol, saccharin sodium, povidone, polyethylene } \\
\text { glycol, sodium citrate, citric acid monohydrate, FD and C red no.3, apricot and } \\
\text { banana flavours and purified water }\end{array}$ & 5.12 \\
\hline Amoxicillin (AM) & Amoxicillin as trihydrateusp $250 \mathrm{mg}$ & 5.08 \\
\hline Medazole (ME) & Metronidazole as benzoyl Bp $200 \mathrm{mg}$ & 6.19 \\
\hline ViTon (VI) & 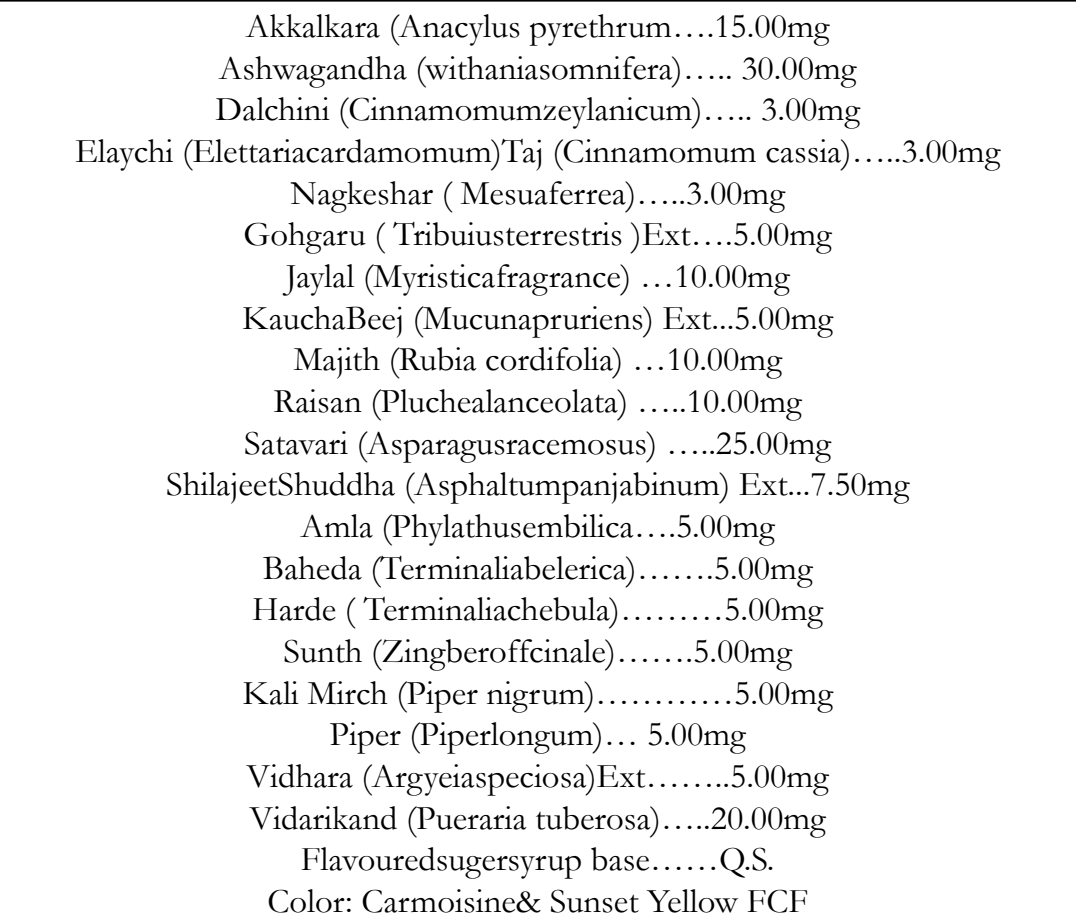 & 4.94 \\
\hline
\end{tabular}


Table 2. Composition of artificial saliva per one liter of water: (Taqa et al., 2019).

\begin{tabular}{|c|c|c|c|}
\hline & Componant & wieght & pH \\
\hline \multirow{4}{*}{$\begin{array}{c}\text { Artificial } \\
\text { saliva }\end{array}$} & $\mathrm{CaCl}_{2}$ & $\left(15 \mathrm{mg}^{* *}\right)$ & \\
\cline { 2 - 3 } & $\mathrm{MgCl}_{2}$ & $\left(5 \mathrm{mg}^{* *}\right)$ & \\
\cline { 2 - 3 } & $\mathrm{KCl}$ & $\left(0.1 \mathrm{~g}^{*}\right)$ & \multirow{2}{*}{7} \\
\cline { 2 - 3 } & $\mathrm{KSCN}^{*}$ & $\left(10 \mathrm{mg}^{* *}\right)$ & $\left(40 \mathrm{mg}^{* *}\right)$ \\
\cline { 2 - 3 } & $\mathrm{Na}_{2} \mathrm{HPO}_{4}$ & $\left(1.0 \mathrm{~g}^{*}\right)$ \\
\cline { 2 - 3 } & sodium carboxymethylcellulose & $\left(0.1 \mathrm{~g}^{*}\right)$ & \\
\cline { 2 - 3 } & \multicolumn{2}{|c}{} & \\
\hline
\end{tabular}

$*_{\mathrm{g} \text { gram }}^{* *}$ mg milligram

Table 3. Comparison of mean tooth weight loss after immersion into each medication and in four intervals of 7 th, 14th, 21th and 28th days.

\begin{tabular}{|c|c|c|c|c|c|c|c|c|}
\hline $\begin{array}{l}\text { Type of medi- } \\
\text { cation }\end{array}$ & $\begin{array}{c}\text { Tooth loss } \\
\text { 7th day } \\
\text { Mean (SD) }\end{array}$ & $\mathrm{P} *$-value & $\begin{array}{c}\text { Tooth loss } \\
\text { 14th day } \\
\text { Mean (SD) }\end{array}$ & $\mathbf{P * \text { -value }}$ & $\begin{array}{c}\text { Tooth loss } \\
\text { 21th day } \\
\text { Mean (SD) }\end{array}$ & P*-value & $\begin{array}{c}\text { Tooth loss } \\
\text { 28th day } \\
\text { Mean (SD) }\end{array}$ & $\mathbf{P} *$-value \\
\hline ViTon & $0.025(0.005)$ & 0.003 & $0.065(0.005)$ & 0.0 & $0.105(0.005)$ & 0.0 & $0.145(0.005)$ & 0.0 \\
\hline $\begin{array}{l}\text { ViTon with } \\
\text { Fluoride }\end{array}$ & $0.008(0.0)$ & 0.0 & $0.025(0.005)$ & 0.003 & $0.055(0.005)$ & 0.0 & $0.080(0.008)$ & 0.0 \\
\hline Amoxicillin & $0.015(0.0)$ & 0.0 & $0.050(0.008)$ & 0.001 & $0.080(0.008)$ & 0.0 & $0.120(0.008)$ & 0.0 \\
\hline $\begin{array}{l}\text { Amoxicillin with } \\
\text { Fluoride }\end{array}$ & $0.005(0.0)$ & 0.001 & $0.015(0.0)$ & 0.0 & $0.040(0.008)$ & 0.002 & $0.070(0.008)$ & 0.0 \\
\hline Paracetamol & $0.010(0.0)$ & 0.0 & $0.040(0.008)$ & 0.002 & $0.070(0.008)$ & 0.0 & $0.110(0.008)$ & 0.0 \\
\hline $\begin{array}{c}\text { Paracetamol with } \\
\text { Fluoride }\end{array}$ & $0.005(0.0)$ & 0.001 & $0.015(0.0)$ & 0.0 & $0.035(0.0)$ & 0.0 & $0.065(0.0)$ & 0.0 \\
\hline Adol & $0.008(0.0)$ & 0.005 & $0.030(0.0)$ & 0.0 & $0.060(0.0)$ & 0.0 & $0.100(0.0)$ & 0.0 \\
\hline $\begin{array}{l}\text { Adol with Fluo- } \\
\text { ride }\end{array}$ & $0.005(0.0)$ & 0.001 & $0.013(0.0)$ & 0.0 & $0.035(0.0)$ & 0.0 & $0.060(0.008)$ & 0.001 \\
\hline Medazole & $0.008(0.0)$ & 0.0 & $0.015(0.0)$ & 0.0 & $0.050(0.0)$ & 0.001 & $0.080(0.008)$ & 0.0 \\
\hline $\begin{array}{c}\text { Medazole with } \\
\text { Fluoride }\end{array}$ & $0.004(0.0)$ & 0.0 & $0.010(0.0)$ & 0.0 & $0.050(0.00)$ & 0.0 & $0.060(0.0)$ & 0.0 \\
\hline Negative Control & $0.001(0.0)$ & 0.0 & $0.002(0.0)$ & 0.0 & $0.004(0.0)$ & 0.0 & $0.005(0.0)$ & 0.0 \\
\hline
\end{tabular}

$$
* \mathrm{P}<0.001
$$

Figure 1. Schematic the Study Design and Sample Grouping.

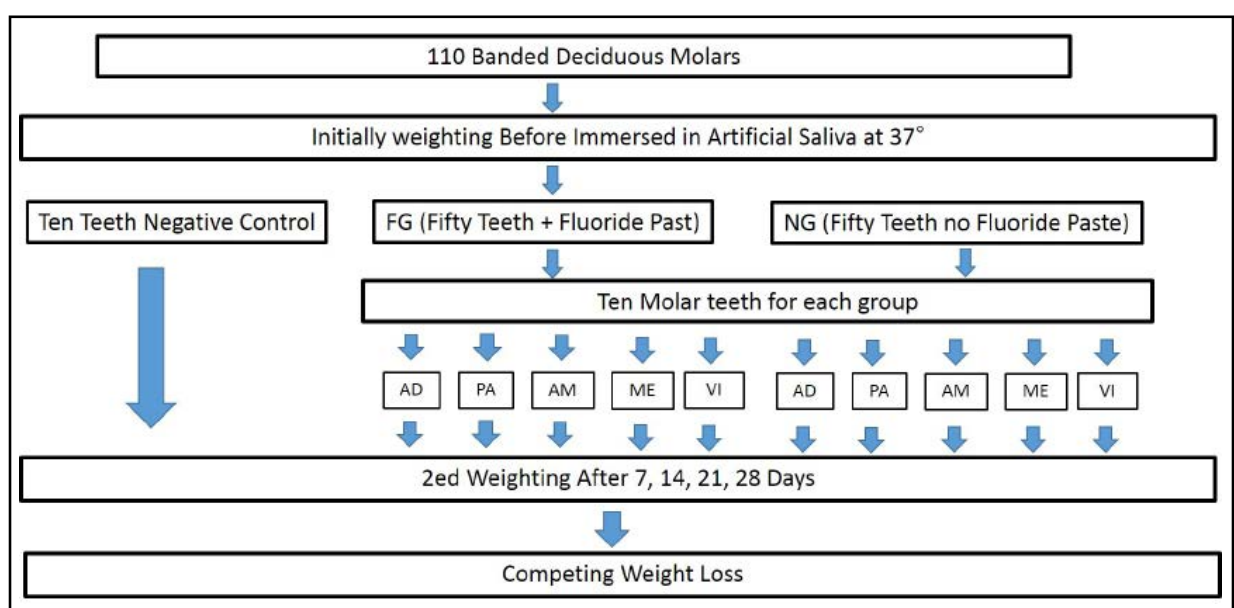


Figure 2. Schematic the Tooth Loss by Weight after Immersion Interval on 7th, 14th, 21th and 28thDays for Fluoridated and non-Fluoridated Groups and for all Used Medications.

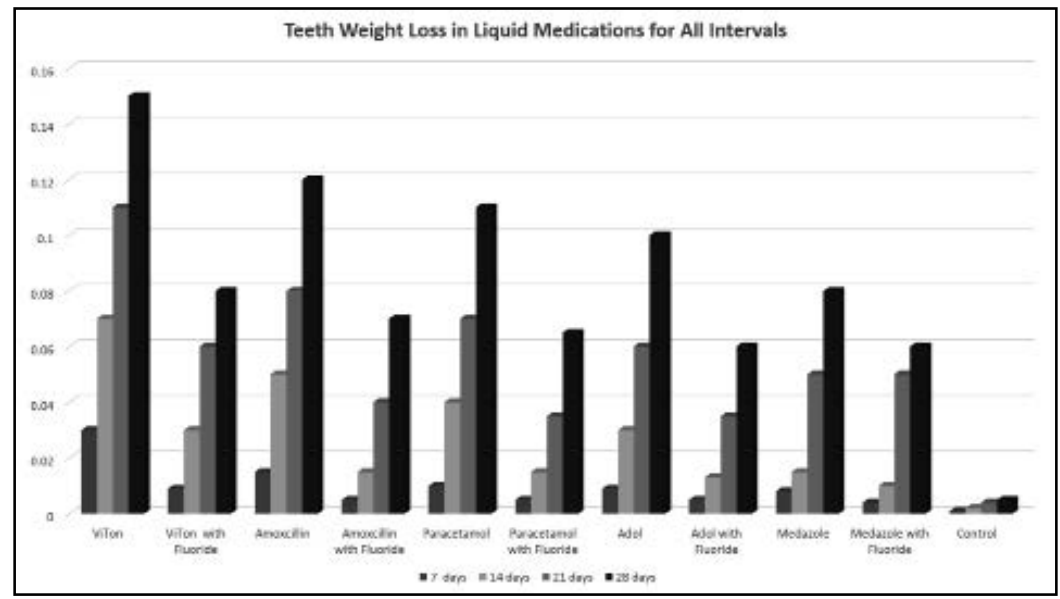

caused by medicine intake. Research on primary teeth substrates are of scientific relevance, as it has been observed that there is a structural and morphological difference between deciduous and permanent teeth. The dissimilarities in the chemical conformation, rate of development and ultra-structurehave been inspected between the pellicle on primary and permanent teeth. Primary enamel is more susceptible to enamel erosion with 50\% more mineral loss and 30\% more lesion depth. The primary enamel is less mineralized and the density of its outermost layer is lesser when compared to permanent teeth [23]. As a result, the loss of the anchor deciduous molars may lead to vital failure of the expansion in palatal constricted maxilla.

We followed previously authorized methods for erosive evaluation and immersion cycle of the oral medications used [17-19].

In the present study, the five investigated syrups have acidic components, which decreased the $\mathrm{pH}$ of the oral cavity and saliva as shown in table 1 . However, present study showed that the $\mathrm{pH}$ of $\mathrm{ME}$ was higher than the $\mathrm{pH}$ of the remaining syrups (6.19). While, the $\mathrm{pH}$ of VI showed the lowest value among all the remaining syrups (4.94), and the $\mathrm{pH}$ of all the pediatric syrups used in the present study were lower than the critical $\mathrm{pH}$ of demineralization, asthe probability of enamel erosion increases withdecreasing $\mathrm{pH}[17]$.

During syrup production, usually the acidsare added to thepreparations as a buffering tool in order to preserveits chemical constancy, in addition to regulate tonicity andcertifyits physiological compatibility. Another reason for acid additionis to enhance flavor, and increase palatability for children [12]. However, citric acid, in spite of its weak acidity, has recently been reported to have the ability to de erosive to the enamel surfaces of the tooth,due to the chelating capability of the calcium in the hydroxyapatites [11].

Our results showed an erosive in the enamel of the banded teeth, which was expressed in this study as a weight loss, in all the tested groups on the $7^{\text {th }}$ day as compared to negative control values. The VI syrups showed the maximum means of weight loss and it was statistically significant. The reason for more weight loss on the 7 thday as compared to negative control group values could be due to syrups exposure. On the other hand, this differencethat observed in different groups could berelated to the variations in the syrups $\mathrm{pH}$, as well as the used acids, the buffers added, and fi- nally could be due to the compositions of the oral liquid medicine [24]. Supposing that the enamel for all the teeth have the same mineralization components.

On the other hand, the recent study indicated that the mean of total tooth weight loss on the $28^{\text {th }}$ day was highest in VI, 0.145 (SD 0.005) and least in ME, 0.080 (SD 0.008). This may be because that $\mathrm{ME}$ has higher $\mathrm{pH}$ than remaining syrups (6.19).

The four weeks (28 days) investigated period was selected, to study the effects of long term administration of the medicine. Particularly, for young children with PE. It is seems that extended treatments could be induced high tooth structure loss, and that could be greater than those marked in this investigation. However, a similar protocol was followed by Amaechi et al. [25] Nevertheless, the oral liquid medicine investigated were nominated because they are routinely prescribed for the treatments ofpublic childhood illnesses.

Similarly to the in vitro study by Scatena et al. [26] who assessed the erosive potential of pediatric liquid medicines in primary tooth enamel, the syrup immersion cycles were done for one minute three times per day, for four weeks. The tooth surface micro hardness was competed at 1, 2, 3 and 4 weeks respectively. Additionally, the scanning electron microscope was used to show tooth surface on the 28th day, which hasa clear exhibited structural loss [26].

The erosive potential of liquid oral medications might be related to the regularity and interval of acid contact, it is also, related to the total volume of syrups ingested. Despite the properties of these oral syrups, the indiscriminate consumptions of children syrups, particularly by young children could increase the dental erosion and tooth loss. Even more, the administration of liquid oral syrups before bed time couldworsen the condition, particularly, if it is not follow by good oral hygiene [27].

The result of current study also showed that increasing of weight loss with time were smaller in all groups used fluoridated tooth paste before exposed to medication. This may attributed to the formation of precipitated calcium fluoride $(\mathrm{CaF} 2)$ that poses a reservoir of fluoride, that released fluoride ions gradually upon acid dose [28], and this also, high light the importance of oral health care with a fluoride supplements especially for young chil- 
dren with cleft palate, under fixed orthodontic therapyby palatalexpander.

Therefore, the using of children's syrup necessitates concentrated oral hygiene measureswith fluoridated tooth paste [29]. As well as, it is well-thought-out that the pharmacological companies should advertise the possibility of tooth erosion on drug leaflet.

\section{Conclusion}

Gravimetric method is valid for detection of the erosive enamel induced by liquid medications on banded deciduous molars, and the Fluoridated toothpaste has a significant reduction of such erosion potential. Majority of children syrups were unaware concerning the sweetening agents and acidity, which cause aggressive effects on the teeth enamel. Also, high care should be considers after prescribing liquid medicaments, especially for young children with constricted maxilla and under fixed orthodontic treatment. Hence, brushing with fluoridated tooth paste should be delivered to enhance the oral health related to the quality of life in such children.

\section{Limitations of the Study}

The limitations of this ex vivo study include: the teeth were immersed for 1 minute in each medication. Usually, without effect of complaint which occur under normal oral conditions during in vivo study. Also, in order to better imitator to clinical conditions, we used $\mathrm{pH}$-cycling model. However, in vitro study might not reproduce the results of an in-vivo one. Besides, the effect of oral factors such as, saliva and dental plaque on the enamel remineralization and mineral loss from tooth surface could not be considered.

\section{Clinical implication of the study}

This study shows the importance of oral hygiene instructions for young children. Especially, for those having Hass expander or even with space maintainer, as the deciduous teeth are encircled with molar bands. The use of fluoridated tooth paste before oral consumption of liquid medicine are highly reduce the erosive potential of the deciduous teeth and increase the survival time of them.

\section{Acknowledgment}

The authors are very grateful to the Collage of Dentistry/ University of Mosul for their provided facilities, which helped improve the quality of this study.

\section{References}

[1]. Foster T. Maxillary deformities in repaired clefts of the lip and palate. Brit J Plastic Surgery. 1962; 15: 182-190. PubmedPMID: 13894251.

[2]. Kutin G, Hawes RR. Posterior cross-bites in the deciduous and mixed dentitions. Am J Orthod. 1969; 56(5); 491-504.Pubmed PMID: 5261162.

[3]. Bishara SE, Staley RN. Maxillary expansion: Clinical implications. Am J OrthodDentofaciOrthoped. 1987; 91(1): 3-14. Pubmed PMID: 3541577.

[4]. Berlocher WC, Mueller BH, Tinanoff N. The effects of maxillary palatal expansion on the primary dental arch circumstance. Pediatr Dent. 1980; 2(1): 27-30:Pubmed PMID:7001393.

[5]. Cohen MM, Orr J, Borell G. Minor tooth movements in in the growing child, Philidelphia; WB Saunders Co, 1977; P 70.
[6]. Cozzani M, Guiducci A, Mirenghi S, Mutinelli S, Siciliani G. Arch width changes with a rapid maxillary expansion appliance anchored to the primary teeth. Angle Orthod. 2007; 77: 296-302.Pubmed PMID:17319765.

[7]. Ugolini A, Cerruto C, Di Vece L, Ghislanzoni LH, Sforza C, Doldo T, et al. Dental arch response to Haas-type rapid maxillary expansion anchored to deciduous vs permanent molars: A multicentric randomized controlled trial. Angle Orthod. 2014;85(4): 570-576.Pubmed PMID:25314034.

[8]. Da Silva Filho OG, Montes LA, Torelly LF. Rapid maxillary expansion in the deciduous and mixed dentition evaluated through postero-anterior cephalometric analysis. Am J OrthodDentofaciOrthop. 1995; 107: 268-275.

[9]. Mutinelli S, Cozzani M, Manfredi M, Siciliani G. Dental arch analysis system. Progress Orthod. 2004; 5:200-208.Pubmed PMID:15546012.

[10]. Jaeggi T, Lussi A. Prevalence, Incidence and Distribution of Erosion. Monographs Oral Sci. 2014; 55-73. Pubmed PMID:24993258.

[11]. Lussi A, Jaeggi T. Erosion-diagnosis and risk factors. Clin Oral Investig. 2008; 12(1): S5-13.

[12]. Maguire A, Baqir W, Nunn JH. Are sugars-free medicines more erosive than sugars-containing medicines? An in vitro study of pediatric medicines with prolonged oral clearance used regularly and long-term by children. Int JPed Dent. 2007; 17(4): 231-238. Pubmed PMID:17559449.

[13]. Alexandria AK, Meckelburg ND, Puetter UT, Salles JT, Souza IP, Maia LC. Do pediatric medicines induce topographic changes in dental enamel? Brazil Oral Res. 2016; 30(1); 11. Pubmed PMID:.26676189.

[14]. Costa CC, Almeida IC, Costa Filho LC. Erosive effect of an antihistaminecontaining syrup on primary enamel and its reduction by fluoride dentifrice. Int JPediat Dent. 2006; 16(3): 174-180. Pubmed PMID:16643538.

[15]. Babu KL, Rai K, Hedge AM. Pediatric Liquid Medications: Do They Erode the Teeth Surface? An In-vitro Study, Part I. J ClinPediatr Dent. 2008; 32(3):189-94.Pubmed PMID:18524267.

[16]. Taqa AA, Sulieman R, Al-Sarraf HA. Artificial saliva sorption for three different types of dental composite resin (an in vitro study).EC Dental Science. 2019:18(10): 2339-2344.

[17]. Kulkarni P, Anand A, Bansal A, Jain A, Tiwari U, Agarwal S. Erosive effects of pediatric liquid medicinal syrups on primary enamel: An in vitro comparative study. Indian J Dent. 2016; 7(3):131-3.Pubmed PMID:27795647.

[18]. Von FraunhoferJA, Rogers MM. Dissolution of dental enamel in soft drinks. General Dent. 2004; 52: 308-312.Pubmed PMID: 15366295.

[19]. Zimmer S, Kirchner G, Bizhang M, Benedix M. Influence of Various Acidic Beverages on Tooth Erosion. Evaluation by a New Method. PLOS ONE. 2015; 10(6): e0129462. Pubmed PMID:26035729.

[20]. Schlueter N, Hara A, Shellis RP, Ganss C. Methods for the measurement and characterization of erosion in enamel and dentine. Caries Res. 2011; 45(1):13-23. Pubmed PMID:: 21625129.

[21]. Shellis RP, Ganss C, Ren Y, Zero DT, Lussi A Methodology and models in erosion research: discussion and conclusions. Caries Res. 2011; 45(1):69_ 77. Pubmed PMID:21625135.

[22]. Linnet V, Seow WK. Dental erosion in children: A literature review. Am AcadPediatr Dent. 2001; 23:1.Pubmed PMID:11242729.

[23]. Pasdor N, Alaghhmand H, Mottagi F, Tavvasoli M. Experimental study of Iron and multivitamin drops on enamel micro hardness of primary teeth. J IntSocPrevCommunit Dent. 2015; 5(6): 518-24.Pubmed PMID:26759808.

[24]. Valinoti AC, Costa Jr, LC, Farah A, Pereira de Sousa V, Fonseca-Gonçalves A, Maia LC. Are Pediatric Antibiotic Formulations Potentials Risk Factors for Dental Caries and Dental Erosion? Open Dent J. 2016; 10(1): 420-430. Pubmed PMID:27583053.

[25]. Amaechi B, Higham S. In vitro remineralisation of eroded enamel lesions by saliva. J Dent. 2001; 29(5); 371-376. Pubmed PMID:11472810.

[26]. Scatena C, Galafassi D, Gomes-Silva JM, Borsatto MC, Serra MC. In Vitro Erosive Effect of Pediatric Medicines on Deciduous Tooth Enamel. Brazil Dent J. 2014; 25(1): 22-27. Pubmed PMID:24789287.

[27]. Cavalcanti AL, Sousa RI, Clementino MA, Vieira FF, Cavalcanti C L, Xavier AF. In vitro Analysis of the Cariogenic and Erosive Potential of Pediatric Antitussive Liquid Oral Medications. Tanzania J Health Res. 2012; 14(2). Pubmed PMID:26591735.

[28]. Ganss C, Schlueter N, Klimek J. Retention of $\mathrm{KOH}$-soluble fluoride on enamel and dentine under erosive conditions-A comparison of in vitro and in situ results. Arch Oral Biology. 2007; 52(1): 9-14. Pubmed PMID:17049481.

[29]. Deepthi M, Mallayya C, Hiremath SK, Srinath J, Nagarathna N. Analysis of Cariogenic and Erosive Potential of Pediatric Antiepileptic Liquid Medicaments: An In vitro Study. IJSR. 2018; 16(2): 169- 174.Pubmed PMID:24939259. 